\title{
Caracterización de la escorrentía superficial de la microcuenca El Estero, San Ramón, Alajuela, Costa Rica
}

\author{
Characterization of the surface runoff of the El Estero \\ microbasin, San Ramón, Alajuela, Costa Rica
}

Marvin Quesada Quesada, Docente catedrático, Sede Occidente, Universidad de Costa Rica, Costa Rica, marvin.quesada@ucr.ac.cr

Kenneth Jiménez Zeledón, Escuela de Geografía, Universidad de Costa Rica, Costa Rica, kenneth.jimenezzeledon@ucr.ac.cr

Resumen: Se ilustra la magnitud del patrón espacial y temporal de acumulación y dirección de la escorrentía en la microcuenca de la quebrada El Estero, en San Ramón, Alajuela, Costa Rica. Esta microcuenca presenta un $30 \%$ de uso rural, con pastos, café, charrales y viviendas aisladas. En contraste existe un $70 \%$ de uso urbano, caracterizado por viviendas, comercios, fábricas y otros servicios. Cuando llueve, las aguas escurren por el pavimento en las calles, aceras y la alta presencia de techos, hacia los caños, alcantarillas, carreteras y por ende hasta el cauce principal de la quebrada. Por medio de información climática, cartografía y análisis hidrológicos es calculado el escurrimiento de la microcuenca El Estero.

Palabras-clave: Precipitación; Escorrentía; Cauce; Impermeabilidad; Microcuenca urbana.

Abstract: It is illustrated the magnitude of the spatial and temporal pattern of accumulation and direction of runoff in the microbasin of the El Estero in San Ramón, Alajuela, Costa Rica. This micro basin has $30 \%$ of rural use, with pastures, coffee, marantaceaes and isolated houses. In contrast there is $70 \%$ urban use, houses, shops, factories, pavement, sidewalks, roofs, existing pipes, sewers and roads that when it rains conduct the waters to the channel of the El Estero. Therefore, through climatological, mapping and hydrological analysis it is calculated the runoff that go to Estero micro basin.

Keywords: Precipitation; Runoff; Channel; Waterproofness; Urban microbasin.

\section{Introducción}

El concepto de cuenca hidrográfica se ha convertido en los últimos veinte años de gran importancia para la planificación, el aprovechamiento, protección, rehabilitación y conservación de los recursos naturales en cualquier sitio del Planeta Tierra (García, Jiménez, 2000). Los eventos hidrográficos que ocurren sobre un determinado espacio geográfico, suelen tener como referencia a la unidad fisiográfica conocida como cuenca, subcuenca y microcuenca, cuyos aportes hídricos naturales están dados exclusivamente por la precipitación. Una parte de la precipitación se infiltra y otra parte se evapora o se acumula en mantos acuíferos o en el subsuelo, sirviendo para las cosechas y a la subsistencia de animales y la vegetación. 
No obstante, existe un alto porcentaje de la lluvia que escurre por los suelos con cobertura impermeable o en periodos de excesiva precipitación, lo que induce a que se origine escorrentía superficial. En muchas ciudades latinoamericanas no han existido buenas prácticas de ordenamiento territorial, puesto que los gobernantes y los encargados de la planificación no piensan que una ciudad debe tener espacios verdes, que aparte de servir para atrapar la contaminación aérea, funcionen también como sitios propicios para captar la precipitación y lograr una correcta percolación (Murillo, 2002).

La mayoría de países de escasos recursos económicos al no tener productos de alta importancia para ser exportados, se tienen que adaptar a los cambios que las grandes potencias o el Fondo Monetario Internacional le pide a cambio para brindar empréstitos. Por consiguiente, un país como Costa Rica, que se encuentra exportando principalmente productos agrícolas como la piña, el banano, la caña de azúcar y el café, por cierto, llamados productos postre (Hall, 1984), o sea, no son de máxima necesidad y que facilmente son suplantados por otros cultivos o artículos que la población los obtiene como prioritarios.

De esta manera, la compra de productos se comporta conforme a los dictados y demanda del mercado internacional. Sumado a lo anterior, cuando dichos productos no tienen un precio competitivo, los propietarios de la tierra los sustituyen por otros usos como lotes para desarrollo inmobiliario. Así se comporta el intenso proceso de urbanización y tercerización del espacio (López-García, Camarasa, Mateu, 2007; Durán, Rodríguez, Francia, Martín, 2014). A consecuencia de estos cambios ha sido la peligrosa alteración del balance del recurso hídrico, que se ha estado dando durante varias décadas.

El mejor ejemplo, lo constituye la ciudad de San Ramón y sus alrededores, que en los últimos cuarenta años ha tenido acelerados cambios en el espacio geográfico. Históricamente gran parte del uso de la tierra ha estado ocupado por el cultivo del café. Dicho producto depende directamente de los precios internacionales, provocando que por su desvalorización sea sustituido en la mayoría de los casos por lotes para uso residencial. Lo que se ha ido visualizando conforme avanzan los años, es una mancha urbana, que se caracteriza por la presencia de una masa impermeable.

El proceso de urbanización conlleva a la reducción de la infiltración, la eliminación de la vegetación natural (que intercepta la precipitación y propicia la evapotranspiración) y la desaparición de formas del relieve como domos, y otros sitios que almacenan el agua precipitada. Se rompe el equilibrio hídrico natural (hidrología superficial y recarga de acuíferos), cuyos efectos más relevantes son: el aumento de los caudales, volúmenes de escorrentía más elevados, el incremento de las inundaciones y la reducción de los caudales base.

Por lo tanto, en esta investigación se hace una ilustración gráfica y cartográfica de la magnitud del patrón espacial, temporal, de acumulación y dirección de la escorrentía en la microcuenca El Estero. 


\section{1. Área en estudio}

El sistema fluvial del río Grande de Tárcoles se divide en dos secciones, al Este el río Virilla y al Oeste el río Grande de San Ramón. La microcuenca Estero se ubica en la segunda Subcuenca hidrográfica. A pesar de su pequeña extensión, comparado con el área de la cuenca donde se ubica, se ha inundado en varias oportunidades y en diferentes años, especialmente en su sector medio y bajo. Esta situación ha sido de gran repercusión social dada la presencia de la ciudad de San Ramón en sus inmediaciones. La microcuenca El Estero abarca un área de aproximadamente $5 \mathrm{Km}^{2}$ y se ubica en la sección más occidental de la Cuenca del río Grande de San Ramón (Figura 1).

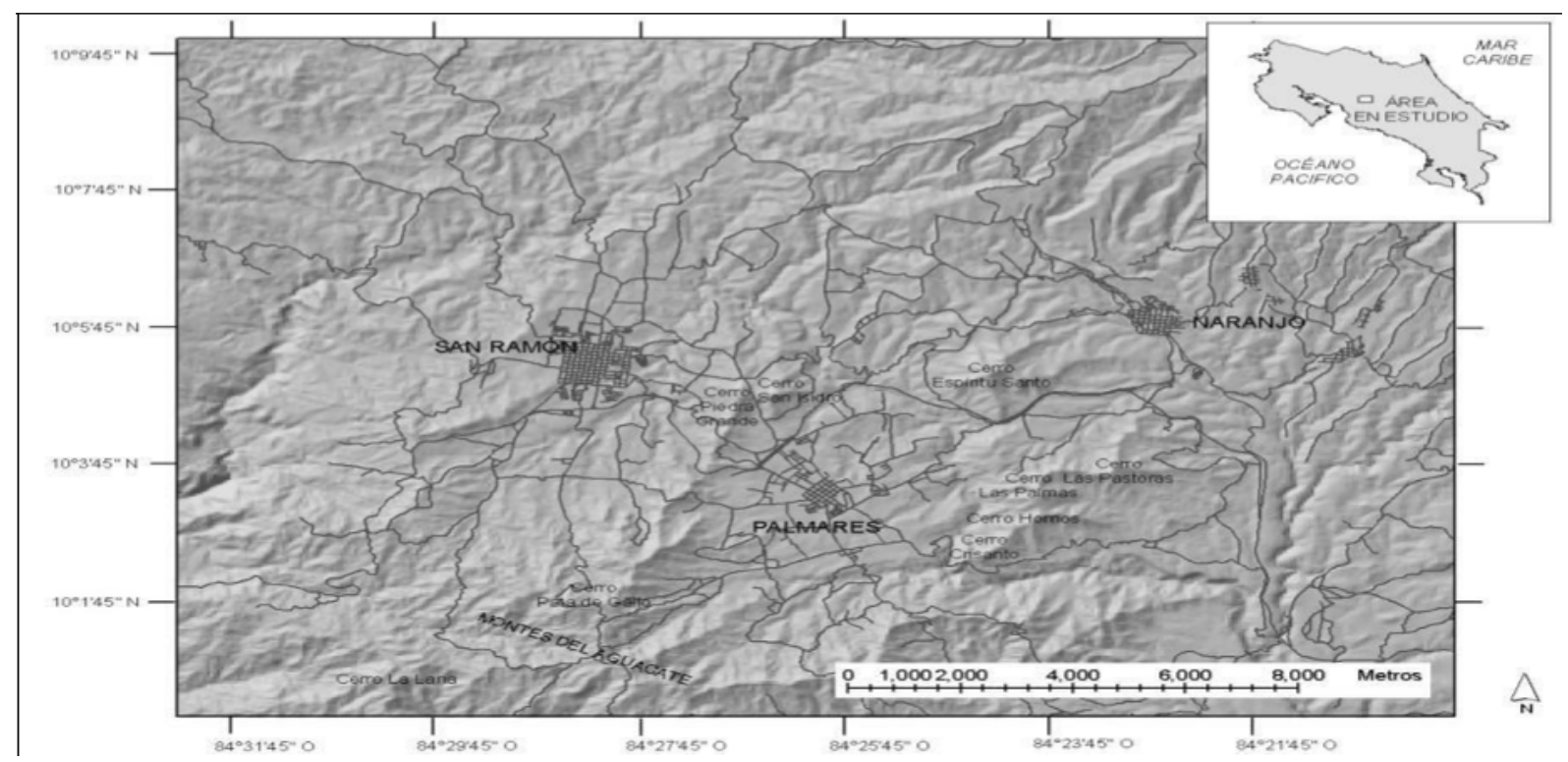

Figura 1: Ubicación de la microcuenca quebrada El Estero en referencia a Costa Rica. Fuente: Elaboración propia con base en la hoja topográfica de Naranjo, 2019.

\section{Metodología}

\subsection{Modelos Hidrológicos y Sistemas de Información Geográficos (SIG)}

Los modelos hidrológicos agrupados promedian los datos de entrada sin consideración de las variaciones espaciales en precipitación, topografía, suelos, y cubierta tierra. Estos modelos usan ecuaciones matemáticas empíricas 0 conceptuales para representar los procesos hidrológicos principales que ocurren en una cuenca. Por el contrario, los modelos distribuidos representan procesos con datos de entrada espacialmente explícitos y el proceso de lluvia-escurrimiento simulado es generalmente basado en los procesos físicos que gobiernan la infiltración y dirigen el escurrimiento hacia un cauce. Los modelos agrupados requieren de registros de precipitación a largo plazo (30 años) y datos de descarga para el proceso de calibración, mientras que los modelos distribuidos, no requieren tan extensa 
calibración porque los parámetros de entrada son basados físicamente (Dykes et al., 2015).

Los modelos de simulación han sido usados en algunos países para simular eventos de tormenta, valoración de la respuesta de inundación por la alteración de la cobertura forestal del suelo. Estos modelos reproducen fielmente la contestación del flujo del arroyo en una lluvia de corta duración y alta intensidad usando cualquier set de datos de precipitación (Durán et al., 2014).

El procedimiento básico seguido es el cálculo de los valores mensuales de escorrentía superficial mediante el uso del método CN (Curve Number) y su integración con el patrón de dirección y acumulación del drenaje, obtenido a través de una simulación que se obtiene a través de una curva de descarga (De Graaff et al., 2013).

Los datos iniciales que sustentan este análisis fueron:

- Información de campo sobre el suelo, mediante información del INTA-CR y por medio de recorridos, donde se localizaron y describieron las clases de suelo.

- Levantamiento topográfico, que corresponde al plano topográfico obtenido del Atlas del Instituto Meteorológico de Costa Rica del 2018, a escala 1:50.000, con curvas de nivel cada $20 \mathrm{~m}$. Este también se puede obtener a nivel de campo.

- Datos puntuales de precipitación, son registros mensuales (estación meteorológica) provenientes del Instituto Costarricense de Electricidad y la Sede de Occidente de la Universidad de Costa Rica. Ambas se ubican dentro de la microcuenca en estudio con un registro superior a 40 años.

La escorrentía superficial se puede representar de la siguiente forma:

Cuadro 1: Características generales según la infiltración y la textura del suelo (NC).

\begin{tabular}{|c|c|c|}
\hline $\begin{array}{c}\text { Grupo } \\
\text { Hidrológico }\end{array}$ & Infiltración/Escorrentía & Textura \\
\hline$A$ & Alta infiltración & $\begin{array}{l}\text { Arenoso, franco } \\
\text { arenoso }\end{array}$ \\
\hline $\mathrm{B}$ & $\begin{array}{c}\text { Moderada infiltración/regular } \\
\text { escorrentía }\end{array}$ & Franco limoso \\
\hline $\mathrm{C}$ & Baja infiltración/Alta escorrentía & Franco arcilloso \\
\hline $\mathrm{D}$ & $\begin{array}{l}\text { Muy baja infiltración/Muy alta } \\
\text { escorrentía }\end{array}$ & $\begin{array}{c}\text { Franco arcilloso y } \\
\text { limoso }\end{array}$ \\
\hline
\end{tabular}

Fuente: Servicio de conservación de suelos de los Estados Unidos (SCS, 1993).

Este ajuste se basa en el hecho que la escorrentía superficial en un mismo suelo puede variar según los niveles de saturación hídrica. La saturación en un perfil según el método CN se estima evaluando la precipitación acumulada durante un mes en el área a analizar. Dado que los datos de precipitación utilizados en este análisis corresponden a una distribución promedio mensual. 


\section{Resultados}

\subsection{Sectorización del tipo de suelo y cobertura}

Los suelos andisoles existentes en la microcuenca El Estero, se caracterizan por su color oscuro, negros por ser de origen volcánico. Se desarrollan a partir de cenizas y otros materiales volcánicos como piedra pómez y lavas. Tienen altos valores en contenido de materia orgánica. Son suelos de texturas medias (franco arenoso y franco limosa) (Figura 2).

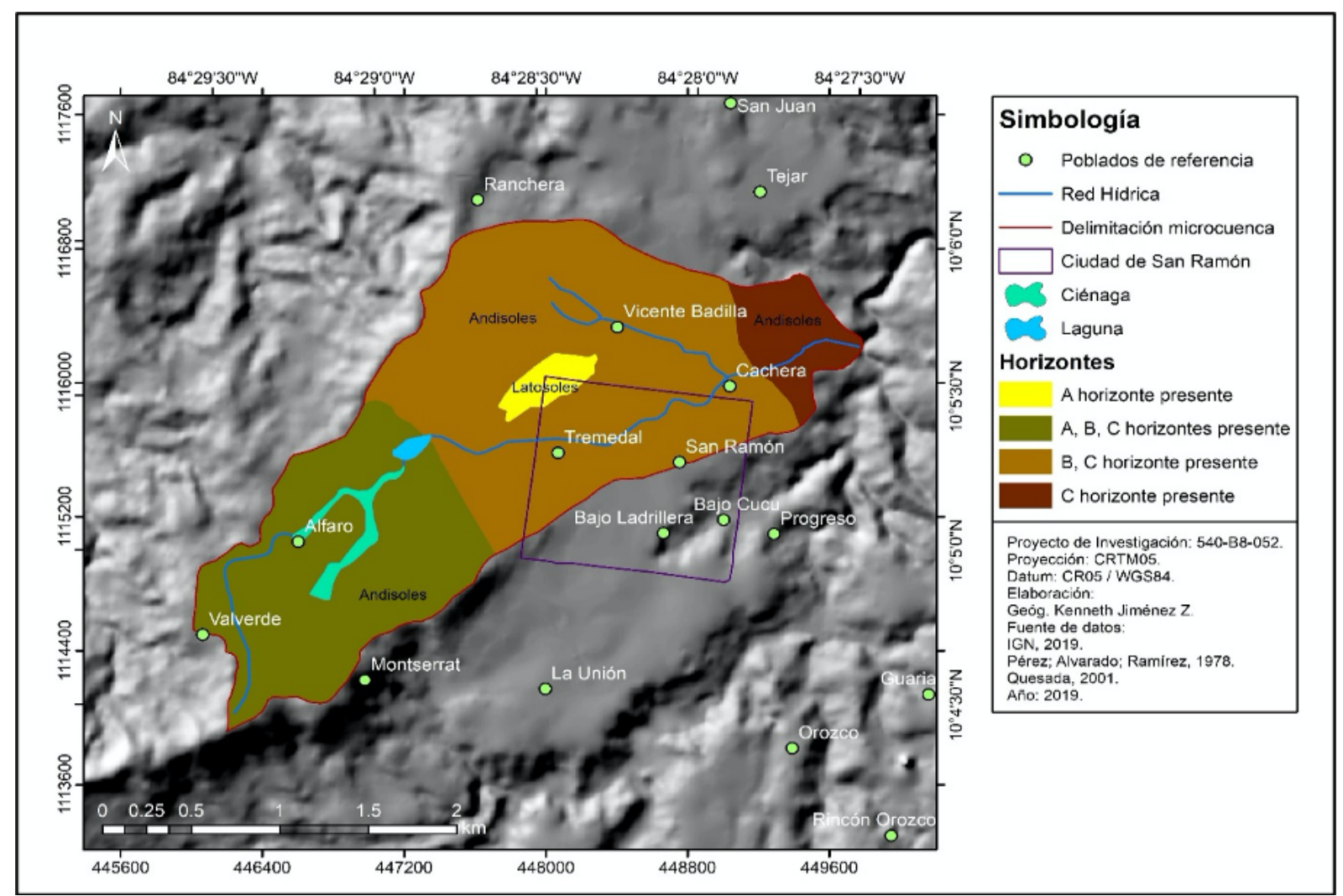

Figura 2: Tipos de suelos en la microcuenca El Estero, San Ramón, Alajuela, Costa Rica.

Fuente: Elaboración propia con base en la hoja topográfica de Naranjo (2019 y otros).

Son suelos de moderada a débil estructuración, se caracterizan por tener un drenaje de bueno a moderadamente excesivo (INTA Costa Rica, 2015), a pesar de tener una capacidad de moderada a alta infiltración. Sólo los suelos que se encuentran en la parte alta de la microcuenca tienen dicha condición, dado que el uso de la tierra es de café, charral y pasto. Sin embargo, dicha característica de infiltración se pierde cuando estos están ubicados en la parte media y baja de la microcuenca.

Los suelos latosoles están poco desarrollados y contienen variedad de fragmentos de rocas. Por lo general, son suelos rojos y profundos, pobremente drenados y con poca permeabilidad. Son suelos arcillosos con muy bajo poder de infiltración, dada su contextura. En la microcuenca El Estero estos suelos cubren poca área, gran parte se ubican bajo el pavimento. 


\subsection{Escurrimiento superficial}

La parte alta de la microcuenca presenta un relieve irregular, aunque por su uso de la tierra presenta una mayor capacidad de infiltración de las lluvias. No obstante, dado el rápido crecimiento de la población, los sectores medio y bajo de la microcuenca están bajo pavimento, carreteras y viviendas, entre otras cosas. Esto induce a que no exista infiltración de las lluvias, lo cual lleva a que el cauce principal de la microcuenca suba su caudal en forma casi inmediata durante el periodo lluvioso.

La producción de escorrentía en cada fecha (1956 y 2011) se ha estimado en relación al umbral de escorrentía, también conocido como P0 (Témez, 1978; Camarasa, Segura, 2001; Borga et al., 2014). Este parámetro hace referencia a la cantidad de lluvia que debe de precipitar para que se produzca escorrentía superficial o flujo Hortoniano.

Además, el sector Oeste (W) cerca del poblado de Alfaro y sobre todo por la barriada de La Ranchera se presentan fuertes pendientes. Estos sectores muestran una parte bajo café, lo cual es un factor beneficioso para la microcuenca, dado que permiten, hasta cierto punto, la percolación de las lluvias. Parte de estos suelos en el mismo sitio están utilizados en viviendas con carreteras pavimentadas, aceras, caños y techos que fluyen con rapidez hasta el cauce principal de la microcuenca.

Como ya se ha mencionado, el umbral de escorrentía depende de las características de la precipitación y de las propiedades de la cuenca de drenaje (Segura, 2014; Camarasa et al., 2006; Zehe, 2009; Durán et al., 2014).

Como se puede observar en la figura 3 y en la figura 4, las fuertes pendientes en sectores con un uso de la tierra de pastos permite en parte que se infiltre el agua de lluvia. Sin embargo, los sectores bajo algún tipo de asentamiento presentan una mayor escorrentía.

Las áreas urbanas y residenciales de San Ramón están concentradas dentro de una región de $3.8 \mathrm{Km}^{2}$ al Este y Oeste de la microcuenca. No obstante, se está expandiendo dentro de las áreas rurales de la microcuenca debido a la población creciente y la limitada disponibilidad de tierra para construcción. Mediante recorridos por el terreno, así como contar con imágenes satelitales, permite observar dicha expansión.

El bosque y la pastura han disminuido durante los últimos cuarenta años de forma radical. La tierra dedicada a la producción del café fue constante en años anteriores, pero como consecuencia de la inestabilidad de los precios en dicho grano, los agricultores y otros dueños de esos terrenos han preferido lotearlos para la venta. Esto ha traído como consecuencia que parte de la población que no cuenta con vivienda propia decida comprar lotes para construir sus viviendas. Esto a su vez perjudica la condición hidrológica de la microcuenca, al existir más techos que escurren sus aguas hacia desagües y caños que luego van a dar al cauce de la quebrada. 
Caracterización de la escorrentía superficial de la microcuenca El Estero, San Ramón, Alajuela Recursos Hídricos e Gestão de Bacias Hidrográficas

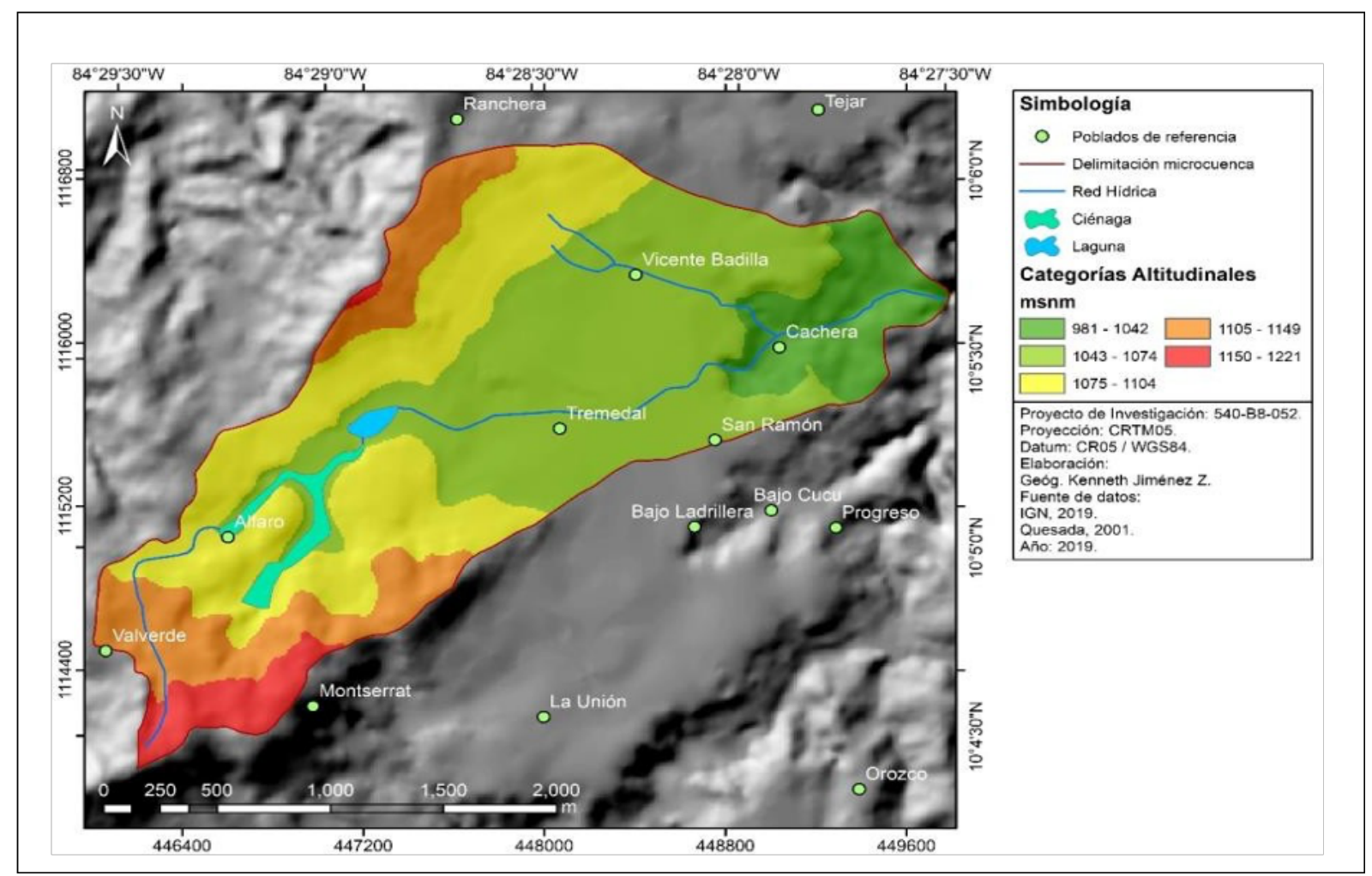

Figura 3: Categorías altitudinales de la microcuenca El Estero, San Ramón, Alajuela, Costa Rica. Fuente: Elaboración propia con base en la hoja topográfica de Naranjo (2019 y otros).

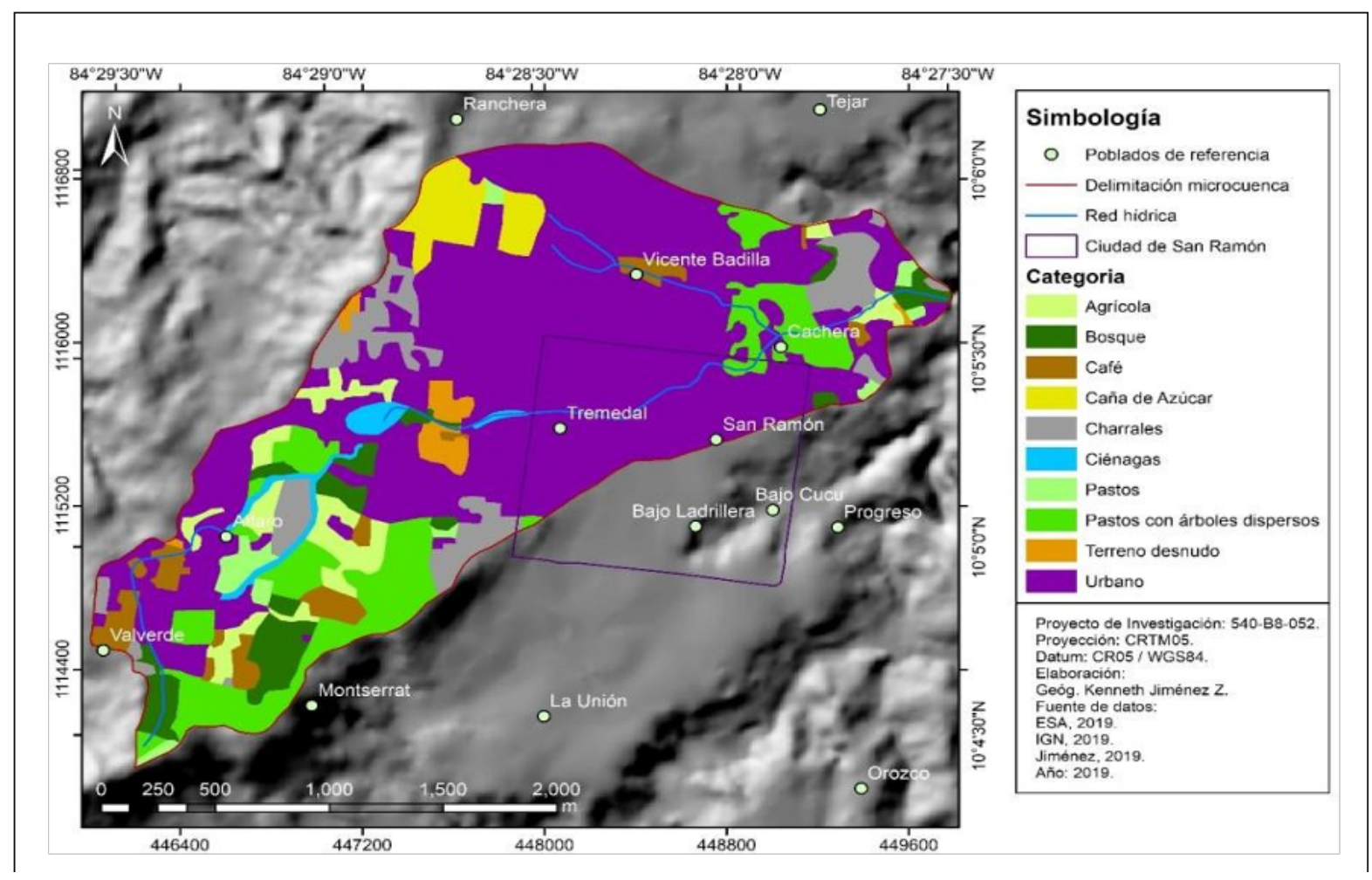

Figura 4: Uso de la tierra en 2019. Microcuenca El Estero, San Ramón, Alajuela, Costa Rica. Fuente: Elaboración propia con base en la hoja topográfica de Naranjo (2019 y otros). 
Con base en los datos promedios mensuales y los valores extremos en la precipitación se tiene que existen dos estaciones climáticas distintas, una estación seca de diciembre a marzo con dos meses de transición que son noviembre y abril y una estación húmeda de mayo a octubre, que prevalecen en San Ramón (Fgura 5). El ambiente topográfico, la elevación y la dirección del viento tienen una influencia dominante en el clima local. En el principio de la temporada húmeda, la migración hacia el norte de la Zona de Convergencia Intertropical (ZCIT) causa precipitación en el flanco Pacífico de Costa Rica (Quesada, Waylen, 2013). Durante este tiempo, la dirección del viento dominante es desde el Oeste, lo cual trae humedad del Océano Pacífico.

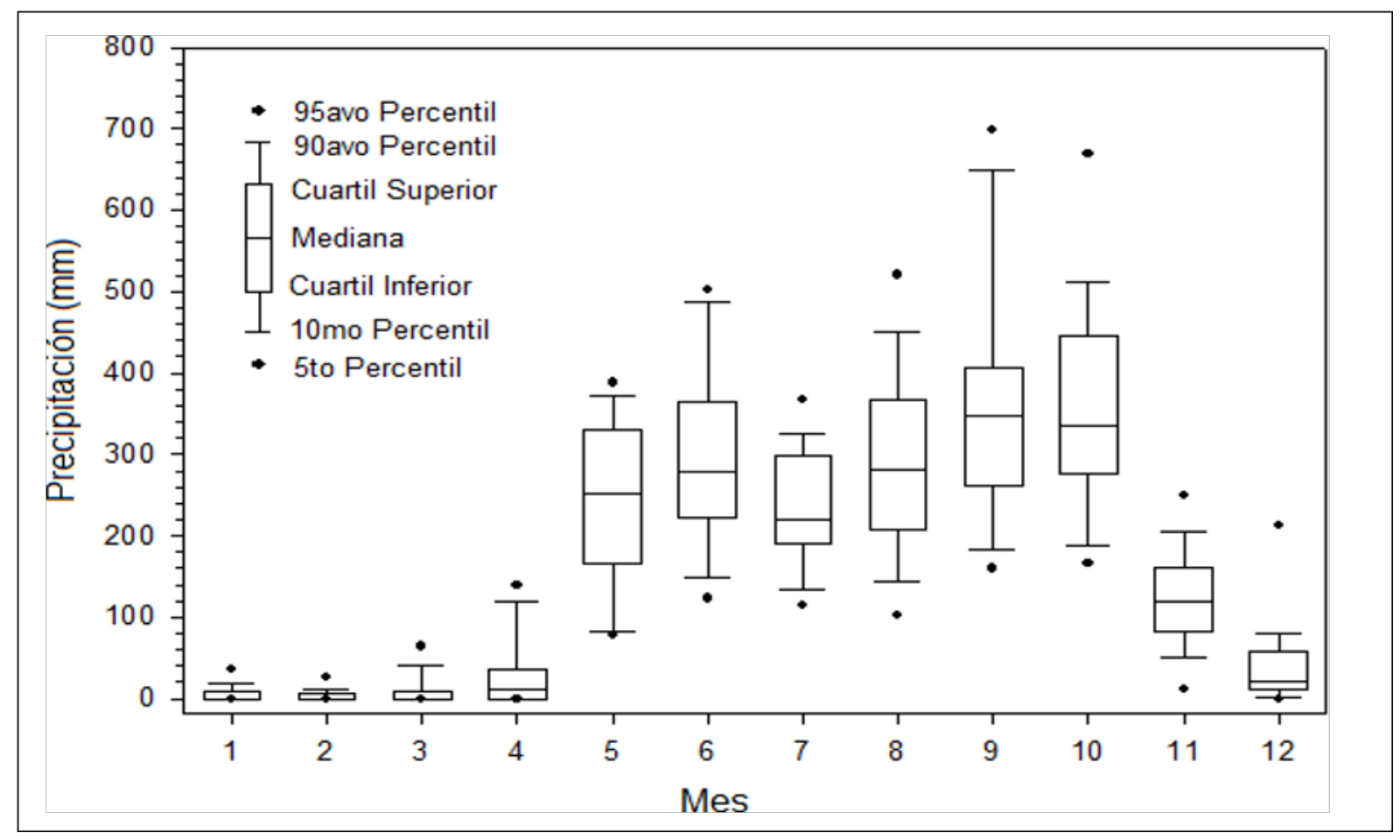

Figura 5: Distribución de la precipitación mensual en la Microcuenca El Estero, San Ramón, Alajuela, Costa Rica.

Fuente: Registros de precipitación del ICE y la Sede Occidente; UCR, 2019.

Sin embargo, durante el "Veranillo de San Juan" y las canículas, ocurre un efímero periodo seco durante algunas semanas de junio, julio y agosto. La dirección del viento desde el Oeste disminuye, mientras que los vientos alisios Nordestes se intensifican. En cambio, al final del año diciembre y enero más bien el viento prevaleciente es del Norte San Ramón. Esto se debe a la existencia de una depresión intermontana que permite el paso de masas de aire (viento, neblina, lluvias) desde el Caribe, a través del Paso de Bajo Tapezco y Alto Villegas en la Sección de la cordillera Central al norte de la ciudad. Esta reducción estacional es un rasgo prominente de la precipitación climatológica a lo largo de Centroamérica. Mientras la (ZCIT) empieza su migración hacia el sur, la precipitación disminuye, y la estación seca empieza a mediados de noviembre. 


\subsection{Descarga en el área en estudio}

Los coeficientes de escorrentía para los meses de mayo-junio y septiembre-octubre franquean el umbral de muy alto potencial de escorrentía. En cuanto al potencial de escurrimiento, definitivamente en los meses de septiembre y octubre son mayores. Esto denota que en el segundo período lluvioso existe una mayor escorrentía superficial en el área.

La poca sostenibilidad del potencial de escorrentía durante el segundo período lluvioso se debe a que los suelos ya están saturados de agua. Esto por cuanto durante la primera máxima de precipitación poco a poco los suelos se van saturando de lluvia. A pesar de la disminución de las lluvias durante algunos días en junio, julio y agosto, las lluvias durante la segunda máxima de precipitación son muy intensas. Esto provoca coeficientes de escorrentía moderados durante la primera máxima y alto durante la segunda máxima.

El alto grado de asociación entre el coeficiente de escorrentía, la precipitación y la escorrentía total, se debe a que el área de estudio es relativamente pequeña. El promedio mensual de precipitación, la poca capacidad de infiltración que tienen los suelos y su condición hidrológica, particularmente se produce sobre áreas impermeables. Esto implica que toda agua de lluvia adicional generara algún nivel de escorrentía, inclusive bajo suelos con algún nivel de permeabilidad de lluvias. La asociación ligeramente mayor en la relación coeficiente de escorrentía/escorrentía total y la precipitación total confirma el carácter determinante del periodo de lluvias en la variación temporal del coeficiente de escorrentía (González, 2004).

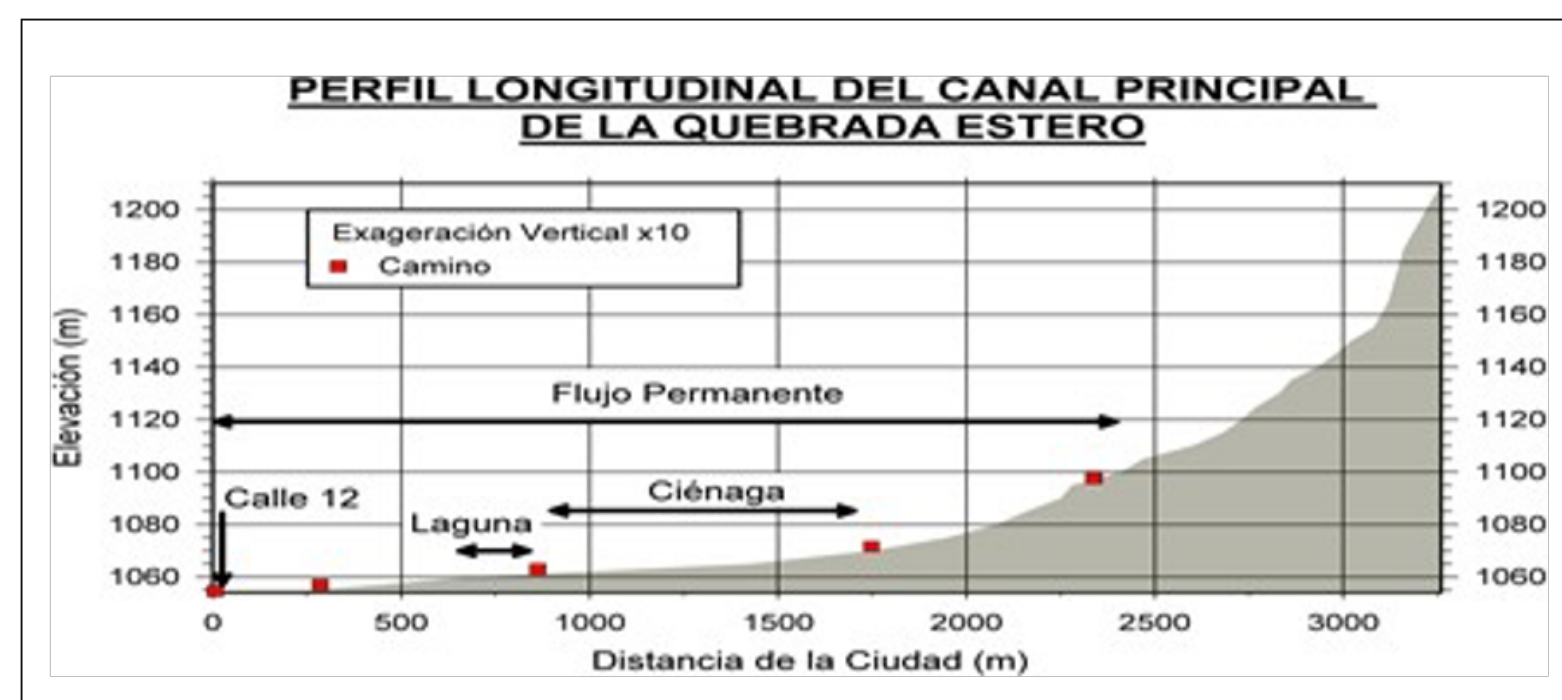

Figura 6: Perfil longitudinal de la Quebrada El Estero, San Ramón, Alajuela, Costa Rica.

Fuente: Elaboración propia, 2019.

Algunos eventos adicionales para el análisis de la quebrada en periodos de intensas lluvias, de acuerdo con la figura 7 señalan con mucha precisión que es muy factible que, bajo fuertes tormentas, un temporal, una onda tropical, un ciclón tropical, entre 
otros, podrían propiciar una inundación al desbordarse la quebrada El Estero. EI "potencial para causar inundación" se basa en que con sólo dos tercios de la profundidad del cauce, o sea con una medida o $0.6 \mathrm{~m}$ en algunos sitios de la quebrada, se produciría una inundación sin precedentes.

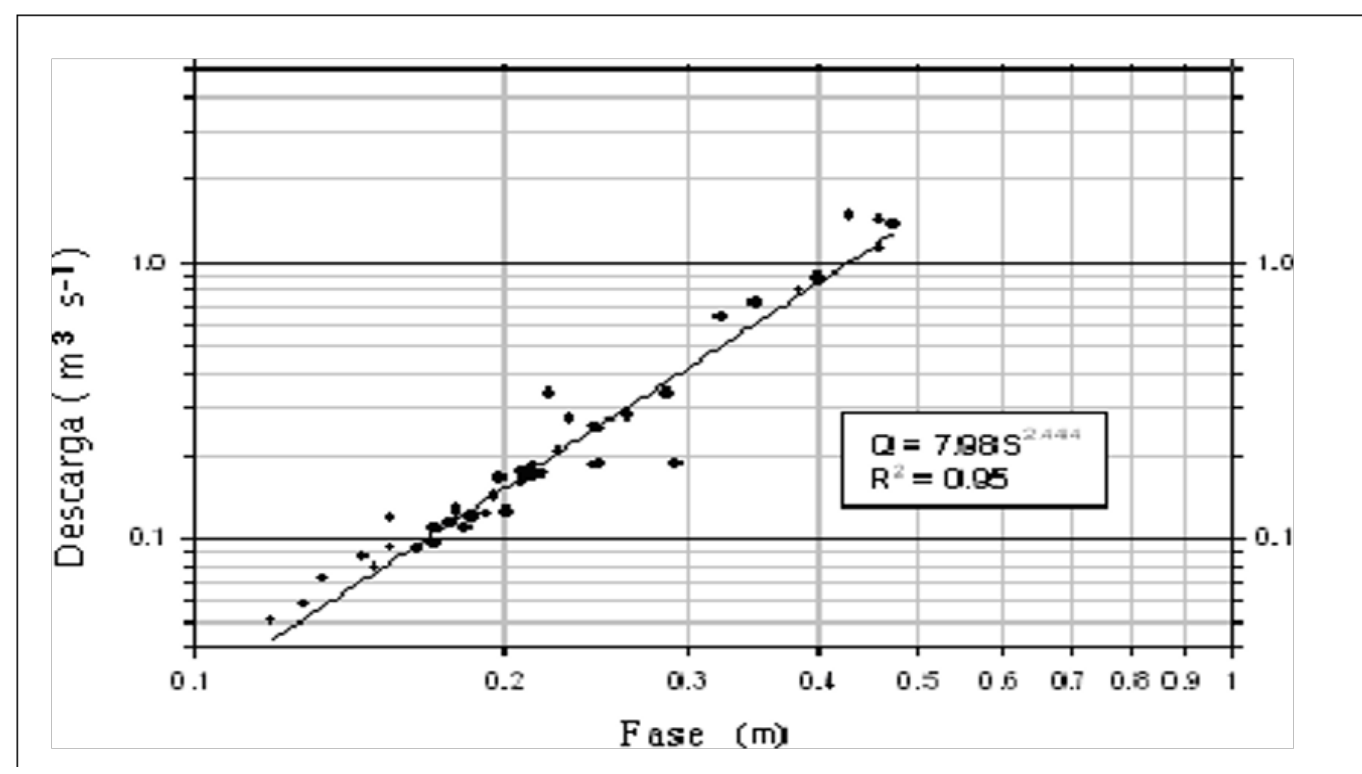

Figura 7: Curva de Valoración Fase-descarga para la Quebrada El Estero, San Ramón, Alajuela, Costa Rica.

Fuente: Elaboración propia con base en los aforos en la Quebrada El Estero, 2019

\section{Discusión y conclusiones}

Una cuenca puede tener una combinación de mecanismos generadores de escurrimiento, subterráneo o superficial o ambos, en los cuales son determinantes las condiciones de la vegetación, las características climáticas, topográficas y del suelo. Los cambios en las condiciones de la cobertura del suelo cambian estos mecanismos de escurrimiento dentro de la microcuenca produciendo pronunciadas respuestas del flujo del arroyo.

Similarmente, serviría para tomar decisiones a nivel del gobierno local y de la Comisión Nacional y local de Emergencias en futuras inundaciones o en casos de excesivos escurrimientos. Esto es típico en algunos sectores, sobre todo en su parte media, que se han dado inundaciones que abarcan gran parte del casco urbano e inclusive varias cuadras (cerca de diez) especialmente hacia el sector norte de la ciudad.

El empleo de un modelo de simulación permitió visualizar la curva de descarga como se hizo en esta investigación. Los datos observados, simulados, los hidrógrafos deben ser evaluados cualitativa y cuantitativamente.

Como es de esperarse, la relación entre el coeficiente de escorrentía $R(Q / p p)$, la escorrentía $Q\left(\mathrm{~m}^{3}\right)$ y el total de precipitación $\mathrm{pp}\left(\mathrm{m}^{3}\right)$, es directa proporcional, con 
coeficientes de correlación de Pearson del orden de 0,7 y 0,8 para las interrelaciones de coeficientes de escorrentía/precipitación total, y coeficiente de escorrentía/escorrentía total, respectivamente.

Las actividades humanas que se realizan en la ciudad de San Ramón producen un gran volumen de residuos de muy diversa naturaleza que en muchos casos son depositados sobre la superficie de la microcuenca como son carreteras, aceras, lotes baldíos y, posteriormente, arrastrados hacia los caños, cauces receptores durante el proceso de precipitación-escorrentía.

Al darse inundaciones tiende a darse una disminución de la diversidad de la vida acuática y la aparición de riesgos para la salud humana y de otros seres vivos Esto por cuanto las aguas de lluvia y los caudales arrastran sedimentos, nutrientes, materia orgánica, metales pesados, patógenos, pesticidas, herbicidas e hidrocarburos, entre otros.

Además, dicha ciudad se desarrolló en las inmediaciones de una quebrada, que en principio fue fuente de agua para uso domestico. Con el pasar de los años, dado el elevado aumento poblacional, ha inducido a un mayor escurrimiento superficial de las lluvias.

En países vecinos se ha encontrado que una pérdida de masa forestal en las cabeceras de las cuencas hidrográficas (López-García et al., 2018), permiten una pérdida de suelo. De acuerdo con Segura (2004) las sociedades instaladas en estos territorios urbanos han ido cambiando el desarrollo de sus actividades, pasando de un aprovechamiento integrado con el medio, a un uso abusivo, sin vegetación, que conduce a la degradación del mismo.

La erosión en la zona de vertido por el rápido incremento de los caudales cuando se produce una lluvia intensa, típica de una nube cumulonimbus, se inicia la socavación del lecho de la quebrada, dado los altos caudales que escurren por los flancos de las vertientes anexas al lecho principal. Esta situación ocurre principalmente en la sección media de la microcuenca. Esto por cuanto, existe una impermeabilización muy alta, dado el incremento de las carreteras, aceras, caños, techos de las viviendas y últimamente, la población tiene como costumbre pavimentar la entrada a las viviendas, en lugar de zacate, dado que en la época lluviosa el zacate tiende a encharcarse.

La parte alta de la microcuenca tiende a contribuir con un alto nivel de sedimentación, que proviene de los sembradíos, de los residenciales que se construyen para gente adinerada que buscan los sitios altos para tener una buena vista hacia la ciudad, en forma de mirador. Los residenciales que existen en este sector se ubican sobre terrenos con un desnivel topográfico.

Tanto los sectores altos como medios contribuyen a que durante el periodo lluvioso se produzcan intensas inundaciones. Estas no sólo ocasionan que rebalse el cauce de la quebrada El Estero, sino que también una serie de viviendas, comercios, servicios, estacionamientos para vehículos y autobuses sufran las inclemencias de dicha quebrada al desbordarse. 


\section{Agradecimientos}

Agradecimiento especial a la Vicerrectoría de Investigación de la Universidad de Costa Rica por el financiamiento parcial de esta investigación. De igual forma se agradece a la Coordinación de Investigación, Sede Occidente por su apoyo.

\section{Bibliografia}

Borga, M., Stoffel, M., Marchi, L., Marra, F., Jakob, M. (2014). Hydrogeomorphic response to extreme rainfall in headwater systems: flash floods and debris flows. Journal of Hydrology, 518, 194-205. http://dx.doi.org/10.1016/j.jhydrol.2014.05.022

Camarasa, A. M., Segura (2001). Flood events in Mediterranean ephemeral streams (ramblas) in Valencia region, Spain. Catena, 45(3), 229-249. http://dx.doi.org/10.1016/S03418162(01)00146-1

Camarasa, A. M., López, M. J., Pascual, J. A. (2006). Análisis mediante SIG de los parámetros de producción de escorrentía. In El acceso a la información espacial y las nuevas tecnologías geográficas (pp. 49-63). Granada: Universidad de Granada.

De Graaff, J., Aklilu, A., Ouessar, M., Asins, V. S., Kessler, A. (2013). The development of soil and water conservation policies and practices in five selected countries from 1960 to 2010. Land Use Policy, 32, 165-174. http://dx.doi.org/10.1016/j.landusepol.2012.10.018

Durán, Z. V. H., Rodríguez, P. C. R., Cuadros, T. S., Francia, M. J. R. (2014). Impacto de la erosión y escorrentía en laderas de agroecosistemas de montaña mediterránea. Ecosistemas, 23(1), 66-72. $\quad$ Retrieved from: https://www.revistaecosistemas.net/index.php/ecosistemas/article/view/820

Dykes, A., Mulligan, M., Wainwright, J. (Eds.) (2015). Monitoring and Modelling Dynamic Environments. John Wiley \& Sons, Ltd. Chichester.

García, J., Jiménez, J. (2000). Manual de Hidrología Forestal. I Descripción física. Escuela Técnica Superior de Ingenieros de Montes, Madrid. 32 pp.

González M., A. (2004). Análisis morfométrico de la cuenca y de la red de drenaje del río Zadorra y sus afluentes aplicados a la peligrosidad de crecidas. Boletín de la A.G.E., 38, 311-329. https://bage.age-geografia.es/ojs/index.php/bage/article/view/495

Hall, C. (1984). Costa Rica. Una interpretación geográfica con perspectiva histórica. Editorial Costa Rica. San José.

Instituto Nacional de Innovación y Transferencia en Tecnología AGROPECUARIA (INTACOSTA RICA). (2015). Boletín técnico número 8. San José, Costa Rica.

López García, M. J., Camarasa, A. M., Mateu, J. (2007). Cambios en los usos del suelo y producción de escorrentía en ramblas mediterráneas: Carraixel y Poyo (1956-1998). Boletín de la AGE 44, 69-94. https://bage.agegeografia.es/ojs/index.php/bage/article/view/610

Murillo, M. E. (2002). Estudio del efecto del cambio de uso del suelo en el escurrimiento en la cuenca 24Bf "Monterrey" aplicando un sistema de información geográfica. Tesis de maestría, División de Ingeniería y Arquitectura, Tecnológico de Monterrey. 
Quesada, M., Waylen, M. (2013). Análisis climático de la precipitación anual e interanual en la cuenca media del río Grande de San Ramón, Costa Rica. Investig. Georg. Chile, 45, 318. http://dx.doi.org/10.5354/0719-5370.2013.27591

Segura, F. (2014). Ramblas y Barrancos: los ríos de piedras. Métode, 38, 109-117. Retrieved from https://metode.es/revistas-metode/monograficos/ramblas-y-barrancos-los-rios-depiedras.html

Zehe, E., Sivapalán, M. (2009). Threshold behavior in hydrological systems as (human) geosiystems: manifestations, controls, Implications. Hydrological Earth System Sciences, 13,1273-1297. http://dx.doi.org/10.5194/hess-13-1273-2009

Artigo recebido em/ Received on: 26/03/2020

Artigo aceite para publicação em/ Accepted for publication on: 02/07/2020 
Quesada e Zeledón / Physis Terrae, Vol. 2, n 1, 2020, 101-113

Página intencionalmente deixada em branco 